\title{
O USO DE ATIVIDADES DE TRADUÇÃO INTERSEMIÓTICA E INTERLINGUAL EM UMA SALA DE AULA DE LÍNGUA INGLESA COMO LE
}

\author{
EL USO DE ACTIVIDADES DE TRADUCCIÓN INTERSEMIOTICA E \\ INTERLINGUAL EN UNA CLASE DE LENGUA INGLESA COMO LE
}
THE USE OF INTERSEMIOTIC AND INTERLINGUAL TRANSLATION ACTIVITIES IN AN EFL CLASSROOM

Sinara de Oliveira BRANCO ${ }^{1}$

Luciana Soares dos SANTOS ${ }^{2}$

RESUMO: Este artigo se propõe a analisar a eficácia do uso da tradução como ferramenta de ensino em sala de aula de língua inglesa como LE através da aplicação de três atividades envolvendo as categorias de tradução interlingual e intersemiótica, propostas por Jakobson (1958, 2000), notas de campo e análise dos resultados das provas aplicadas. Foi observado o impacto do uso da tradução como ferramenta na aprendizagem dos alunos. O suporte teórico utilizado envolve Leffa (1988), Romanelli (2006) e Lucindo (2006, 2009). A organização dos dados caracterizou uma metodologia de natureza qualitativa e uma pesquisa-ação. O corpus é formado pelas atividades, questionários e respostas dos alunos às atividades e aos questionários aplicados. Os resultados indicam que o estudo das categorias de tradução como ferramenta no ensino de LE, quando usadas de forma criteriosa, pode ser de grande auxílio para professores e alunos, tornando a prática da tradução neste contexto justificável e positiva.

PALAVRAS-CHAVE: Tradução e abordagens de ensino. Categorias de tradução. Exercícios de tradução. Ensino de inglês como LE.

RESUMEN: Este artículo se propone analizar la eficacia del uso de la traducción como herramienta de enseñanza en el aula de lengua inglesa como LE através de la aplicación de tres atividades elaboradas con las categorías de traducción interlingual e intersemiótica propuestas por Jakobson (1958, 2000), notas y análisis de los resultados de las pruebas aplicadas. Se observó el impacto del uso de la traducción como herramienta en el aprendizaje de los alumnos. El soporte teórico utilizado envuelve Leffa (1988), Romanelli (2006) y Lucindo (2006, 2009). La organización de los datos caracterizó una metodología de naturaleza cualitativa y una investigación-acción. El

\footnotetext{
${ }^{1}$ Universidade Federal de Campina Grande (UFCG), Campina Grande - PB - Brasil. Professor Associado. Curso de Graduação de Licenciatura em Letras-Inglês e Programa de Pós-Graduação em Linguagem e Ensino (POSLE). Unidade Acadêmica de Letras. Doutora pelo Programa de Pós-Graduação em Inglês, Universidade Federal de Santa Catarina - (UFSC). E-mail: sinarabranco@ gmail.com.

${ }^{2}$ Universidade Federal de Campina Grande (UFCG). Professora de Inglês. Oxford - Escola de Idiomas. Graduada em Letras-Inglês. E-mail: luh93@hotmail.com.
} 
corpus está formado por las actividades, cuestionarios y respuestas de los alumnos a las actividades ya los cuestionarios aplicados. Los resultados indican que el estudio de las categorías de traducción como herramienta en la enseñanza de LE, cuando se utilizan de forma cuidadosa, puede ser de gran ayuda para profesores y alumnos, haciendo la práctica de la traducción en este contexto justificable y positiva.

PALABRAS CLAVE: Traducción y enfoques de enseñanza. Categorías de traducción. Ejercicios de traducción. Enseñanza de inglés como LE.

ABSTRACT: The objective of this paper is to analyze the use of translation as a tool in EFL teaching. Through the application of three activities involving the interlingual and the intersemiotic translation categories proposed by Jakobson (1958, 2000), field notes and the analysis of assessment results, the impact of the use of translation as a teaching tool on students' learning was investigated. The theoretical framework used involves scholars such as Leffa (1988), Romanelli (2006), Lucindo (2006, 2009) and Malmkjaer (1998). Data organization indicates a qualitative methodology and an action research. The corpus is organized by the students' answers to activities and the answers to the questionnaires. Results have shown that the study of translation categories as a tool in EFL teaching, when used adequately and with specific goals, can be helpful for teachers and students, making the use of translation in this context justifiable and positive.

KEYWORDS: Translation and teaching methods. Translation categories. Translation exercises. English as a foreign language teaching.

\section{Introdução}

A tradução como uma ferramenta para o ensino e aprendizado de uma língua estrangeira (doravante LE) tem sido tema de pesquisa e de aplicação em salas de aula de língua inglesa de escolas no estado da Paraíba. Ao consideramos o uso da tradução em sala de aula, é necessário levar em conta o objetivo da tradução, o nível de conhecimento da LE entre os alunos presentes na turma, a faixa etária desses alunos, bem como o objetivo de aplicação de tal atividade. É necessário que o professor tenha conhecimento do uso das categorias de tradução propostas por Jakobson $(1958,2000)$ que serão inseridas neste contexto e observar sua eficácia.

Ao longo dos anos, a tradução foi considerada inadequada como uma ferramenta em ambientes de English as a Second Language (ESL). Popovic (2001) afirma que essa visão tem mudado devido à função de ferramenta pedagógica legítima que a tradução tem assumido, especialmente no contexto de inglês como LE. Sendo assim, é 
importante questionar o objetivo do uso da tradução em sala de aula e suas implicações para um melhor aprendizado da língua.

Em contexto de sala de aula de língua inglesa em uma escola regular da rede privada de ensino na cidade de Lagoa Seca/PB, é preciso considerar o fato de que os alunos possuem um conhecimento limitado do idioma. Esse é um aspecto relevante a ser considerado na preparação de atividades envolvendo tradução, podendo dificultar determinados tipos de atividade. Em sala de aula, os alunos fazem uso da tradução para a decodificação de signos, compreensão de instruções e em relações pessoais. Dessa forma, visando à aprendizagem de língua inglesa pelos alunos, o uso da tradução como ferramenta de ensino e aprendizagem faz-se necessário, uma vez que tal prática é uma atividade de comunicação da vida real, como explica Popovic (2001, p. 1).

As turmas escolhidas para a aplicação das atividades encaixam-se no conceito de mixed-abilities. Ainslie (1994 apud SVARD, 2006) define mixed-abilities como a sala que inclui alunos que diferem em habilidade, motivação para aprender inglês, necessidades, interesses, histórico educacional, estilos de aprendizagem, experiências, dentre outros aspectos. Tal peculiaridade exerce influência no ensino, no aprendizado e, consequentemente, no planejamento do professor. O processo de planejamento, bem como a aplicação de tais atividades, implica em uma análise acerca do uso da tradução em um ambiente onde a língua inglesa é ensinada como LE.

Seguindo os pontos acima, o objetivo deste artigo é analisar a eficácia da tradução como ferramenta em sala de aula de língua inglesa, através de atividades de tradução. A partir dos objetivos traçados buscaremos: i) aplicar atividades em sala de aula de língua inglesa como LE envolvendo as categorias de tradução interlingual e intersemiótica para a interpretação de textos verbais e não verbais; ii) investigar a eficácia dessas atividades de tradução como ferramenta para a aprendizagem de língua inglesa como LE a partir da aplicação de questionários, de notas de campo e de análise das provas bimestrais. Para atingir tais objetivos, foram elaboradas três atividades de tradução envolvendo escrita, leitura e escuta para auxiliar alunos de oitavo e nono anos de uma escola da rede privada de ensino na aprendizagem da língua inglesa. Além disso, foram aplicados três testes de verificação ou reforço de aprendizagem após a análise e correção das atividades propostas. 


\section{A tradução e as abordagens de ensino}

De acordo com Leffa (1988), Romanelli (2006, 2009), Lucindo (2006) e Malmkjaer (1998), desde o século XIX, a tradução é uma questão central na aprendizagem de LE, partindo do ensino de línguas clássicas como o grego e o latim, sendo considerada instrumento metodológico que constituía o núcleo da Abordagem Gramática e Tradução (AGT). Segundo a AGT os três principais passos para a aprendizagem da LE eram: “ (a) memorização prévia de uma lista de palavras, (b) conhecimento das regras necessárias para juntar essas palavras em frases e (c) exercícios de tradução e versão" (LEFFA, 1988, p. 214).

Embora a AGT tenha sido a abordagem com mais tempo de uso, ela sofreu severas críticas e ao longo dos anos surgiram outras abordagens e métodos como: a Abordagem Direta, a Abordagem de Leitura, a Abordagem Audiolingual, a Abordagem Comunicativa. Nessas abordagens a tradução ocupou diversos papeis na sala de aula, indo de pilar central na AGT, passando por períodos de condenação, como na Abordagem Direta, dividindo opiniões na Abordagem Comunicativa e aos poucos vem retomando seu lugar na sala de aula de LE com o Pós-Método.

O Pós-Método postula que o objetivo da aula é o ensino da língua, mesmo que isso signifique reavaliar e modificar a postura do professor de diversas maneiras, por diversas vezes. A partir do princípio de que o professor deve extrair das abordagens o que acha mais pertinente para a sua aula, adequando o ambiente à realidade de seus alunos, é possível ver que nessa metodologia há um espaço para a prática da tradução em sala de aula. Se o professor percebe que usar a LM em suas aulas irá lhe auxiliar na prática do ensino e também irá tornar o processo de aprendizagem de seus alunos mais fácil, ele é livre para usá-la.

Considerando esse argumento, é relevante mencionar que ao fazer uso da prática de tradução em sala de aula é interessante que o professor saiba como usar a tradução ao seu favor. Dessa forma, o conhecimento a respeito das categorias de tradução propostas por Jakobson $(1958,2000)$ é relevante, para que a prática da tradução seja feita de uma maneira positiva. Os conceitos relacionados a cada categoria serão apresentados a seguir. 


\section{As categorias de tradução e seu uso}

Os Estudos da Tradução vêm ocupando um espaço de destaque como campo de estudo de LE e têm levantado uma questão em torno da importância de se utilizar a tradução em sala de aula. Essa discussão está ligada ao que Jakobson (1958, 2000) chama de categorias de tradução. Segundo o autor, existem três maneiras de interpretar um signo verbal: na mesma língua, em outra língua ou em outro sistema de símbolos não verbais, que são chamadas, respectivamente, de tradução intralingual, interlingual e intersemiótica.

A tradução intralingual trata da interpretação de signos verbais por meio de outros signos verbais na mesma língua, ou seja, não existe uma língua de partida ou de chegada. Jakobson (2000, p. 114) afirma que "a tradução intralingual de uma palavra utiliza outra palavra, mais ou menos sinônima, ou recorre a um circunlóquio". A tradução intralingual assemelha-se a uma paráfrase, reformulando-se o que se diz até que se chegue à devida compreensão. Esse tipo de tradução é algo que fazemos até mesmo em nossa LM.

A tradução interlingual, por sua vez, consiste na interpretação dos signos verbais através de outra língua. Essa categoria de tradução possui uma língua de partida e outra de chegada. No trabalho realizado, o que é apresentado de forma oral ou escrita na língua estrangeira (língua inglesa) é reformulado na língua materna (língua portuguesa brasileira). É importante enfatizar que, sendo um grupo de alunos iniciantes, a direção da tradução deve ser da língua estrangeira para a língua materna e não o inverso, pela dificuldade que os alunos apresentam com relação à LE. A tradução interlingual é comum em níveis iniciais de aprendizado, quando o aluno ainda não possui conhecimento suficiente sobre a LE para manter um diálogo, por exemplo, e precisa perguntar como se diz a palavra " $x$ " na referida língua; ou o que significa " $y$ " em português brasileiro. Na tradução interlingual, Jakobson (2000) explica que muitas vezes o que é reproduzido na língua de chegada é apenas uma interpretação do que foi dito na língua de partida, sem uma correspondência total. $O$ contexto cultural pode justificar o argumento do autor, pois, linguisticamente falando, as distinções culturais do contexto de língua inglesa e língua brasileira não são similares. Nesse caso, faz-se necessário buscar aproximações interpretativas que auxiliem os alunos na compreensão do significado cultural exposto. 
Por fim, a tradução intersemiótica trata da interpretação dos signos verbais por meio de signos não verbais e vice-versa. Nessa categoria, o uso de imagens ganha relevância, pois é explorado com maior frequência, às vezes para evitar a tradução interlingual; outras vezes por já se apresentar uma imagem que gere uma discussão e trabalho específico com um tema específico, por exemplo. A tradução intersemiótica é usada em sala de aula, no ensino de vocabulário, pois o uso do recurso visual pode tornar a assimilação mais imediata. Zainurrahman (2009 apud BRANCO, 2014) enfatiza que atividades visuais maximizam o desenvolvimento na LE, ajudando alunos a memorizar a língua e professores a gerenciar, organizar e ministrar suas aulas. Isso acontece pela questão visual e pela questão do signo, como trata Jakobson (1958, 2000). A interpretação acontece a partir de um raciocínio em signos - ora verbais, ora visuais. A tradução intersemiótica atua nesse contexto, impulsionando o raciocínio dos alunos para que compreendam e memorizem o que é apresentado a partir da exposição visual.

Aumont (1993) afirma que toda representação, seja ela imagética ou verbal, é relacionada pelo espectador (neste caso, pelos alunos) a enunciados culturais, ideológicos, simbólicos, sendo esses o que dá sentido ao que é exposto - verbal ou imageticamente. Com relação especificamente à imagem, Aumont (1993) reforça a necessidade de haver relação entre imagem e palavra, entre imagem e linguagem verbal, pois a imagem não é 'pura', puramente icônica, uma vez que para que haja compreensão plena é preciso haver o domínio da linguagem verbal. Neste caso, a imagem auxiliará a busca da compreensão e do desenvolvimento e domínio da língua inglesa. Em outras palavras, "a imagem só tem dimensão simbólica tão importante porque é capaz de significar - sempre em relação com a linguagem verbal” (AUMONT, 1993, p. 256).

Em níveis iniciais de aprendizagem da LE é habitual que os alunos recorram a sua LM, podendo haver influência da mesma. Tal influência pode ser considerada negativa por professores em geral no que diz respeito ao desenvolvimento do aluno na LE, porém, Branco (2009) afirma que a influência da LM no aprendizado de LE pode ser aproveitada para apresentar características de ambas LM e LE, fazendo com que aos poucos o aluno perceba que não é possível haver total equivalência entre línguas. Caracteriza-se, assim, uma busca para converter a interferência antes tida como negativa em um aspecto positivo. Branco (op. cit.) esclarece que a tradução pode ser usada não só para explicação de conteúdo específico, mas também como exercício. Porém, tal uso 
deve ser controlado e restrito a determinadas situações. É importante que o professor direcione sua aula e suas atividades às necessidades de seus alunos, utilizando a tradução apenas como ferramenta para a sua aula. Partindo desse princípio, é relevante considerar as categorias de tradução propostas por Jakobson (2000) como aspectos importantes, quando houver a prática de tradução em sala de aula de LE. Branco (2009) afirma ainda que Jakobson considera não só a tradução de textos verbais de uma língua de partida para uma língua de chegada (tradução interlingual), mas também o uso de paráfrases (tradução intralingual) e o uso de figuras, gestos e expressões faciais para expressar determinada ideia na LE (tradução intersemiótica). Sobre o uso da tradução, a autora afirma que "a tradução entre línguas pode ocorrer em situações e atividades específicas, sem causar prejuízo ao desenvolvimento do trabalho de sala de aula, desde que bem preparada e com objetivos claros, tanto para o professor quanto para o aluno" (BRANCO, 2009, p. 190).

No entanto, apesar dos aspectos positivos do uso da tradução em sala de aula de LE, é importante observar que tal uso não deve ser excessivo. Gabrielatos (1988 apud KIMINAMI; CANTAROTTI, 2014) explica:

\footnotetext{
A tradução como ferramenta de ensino precisa levar em consideração uma variedade de diferentes aspectos como a gramática (como a transitividade dos verbos), sintaxe, collocations e conotação. O uso acrítico da tradução pode dar aos aprendizes informações insuficientes, confusas ou até mesmo imprecisas sobre a LE. Como resultado dessa contínua frustração eles podem perder o interesse em aprender inglês (GABRIELATOS, 1998 apud KINIMINAMI; CANTAROTTI, 2014, p. 44).
}

Dessa maneira, conhecendo as categorias de tradução propostas por Jakobson (2000), o professor pode usá-las a seu favor, como ferramenta de ensino, a fim de direcionar a prática da tradução em sala de aula e atender às necessidades de seus alunos. Logo, o professor pode propiciar um conhecimento da língua que vá além das estruturas gramaticais.

\section{A tradução como ferramenta no planejamento de atividades}

O planejamento de atividades é uma fase importante para que a prática da tradução seja efetuada com êxito. A partir da Abordagem Funcionalista de Nord (1997), 
Branco (2010, p. 5) afirma que é possível compreender que a "atividade pode ser vista como uma ponte que conecta duas pessoas separadas pela barreira linguística e/ou cultural". Em outras palavras, a Abordagem Funcionalista foca nas atividades de tradução direcionadas ao leitor, considerando o leitor, a função do texto traduzido e o contexto em que ambos estão inseridos. Branco (2010) explica que essa abordagem vê como prioridade o objetivo da tradução, considerando a mesma como uma recriação e não só uma transferência do texto original. Levando em conta tal afirmação, pode-se dizer que é de grande relevância refletir sobre o porquê de usar a tradução em determinado contexto, considerando o ambiente, os alunos e o propósito da atividade de tradução.

A tradução em sala de aula pode ser caracterizada de duas formas: tradução interiorizada e a tradução pedagógica, como define Hurtado Albir (1988 apud LUCINDO, 2006). A tradução interiorizada é definida como um tipo de tradução feita por todo aprendiz de LE. Tal prática de tradução é justificada pelo fato de a LM ser o ponto de referência dos alunos e tudo que os mesmos constroem ou desconstroem é através de sua LM.

A tradução pedagógica, por sua vez, é utilizada como instrumento pedagógico, e é nela que iremos nos ater mais profundamente. Cervo (2003 apud LUCINDO, 2006, p. 4) explica que tal termo foi criado e definido como sendo a "utilização de exercícios escolares visando à aquisição de uma LE". Logo, o objetivo da tradução pedagógica vai além de comunicar ao aluno do teor de um texto traduzido e visa reforçar sua aprendizagem. Assim, toda atividade elaborada pelo professor que envolva alguma prática de tradução, seja através de tradução intralingual, interlingual ou intersemiótica, caracteriza o uso de tradução pedagógica.

Segundo Lucindo (2006), a tradução pedagógica pode existir de duas formas: a tradução explicativa e os exercícios de tradução. Os exercícios de tradução, por sua vez, são uma prática recorrente em sala de aula no ensino de LE, que podem ser de tradução direta ou inversa. O papel do professor nesse tipo de tradução é primordial, pois cabe a ele planejar o exercício, aplicar e corrigir o mesmo. Ainda na fase de planejamento do exercício é importante que o professor esteja atento para a escolha do tópico a ser trabalhado e quais recursos irá usar. Popovic (2001) apresenta a ideia de que, para incentivar o aprendizado de adolescentes, por exemplo, é preciso trazer atividades e 
assuntos que sejam de interesse deles, pois só assim eles se sentirão à vontade para participar da aula e de aprender.

Lucindo (2006) explica que ao utilizar a tradução em sala, o professor desempenha uma função social, pois nas discussões das atividades de tradução deve ser explicado que não há uma única tradução correta, promovendo assim um equilíbrio de poder em sala de aula. Além disso, Hurtado Albir (1988 apud LUCINDO, 2006) afirma que os exercícios de tradução devem trazer interesse linguístico e extralinguístico. A partir desses critérios desenvolvemos atividades de tradução que pudessem ajudar alunos dos últimos anos do Ensino Fundamental II na compreensão dos conteúdos estudados durante o primeiro e segundo bimestre de 2016.

\section{O planejamento das atividades}

As atividades elaboradas para a coleta de dados foram planejadas contemplando as categorias de tradução interlingual e intersemiótica. Portanto, iremos nos ater apenas a essas, visto que o contexto em que a aplicação aconteceu envolve alunos de fases iniciais no aprendizado de inglês como LE. Por essa razão, o uso da tradução intralingual tornaria o processo de aprendizagem mais difícil e, possivelmente, frustrante para os alunos.

O planejamento e a aplicação das atividades aconteceram paralelamente às aulas, assim, as atividades visavam auxiliar os alunos no aprendizado de algum conteúdo lecionado no bimestre. Por exigência da escola, os alunos precisam de duas atividades avaliativas no bimestre. Por essa razão, as atividades de tradução realizadas em sala de aula tiveram também um caráter avaliativo. Todas as atividades foram realizadas antes de uma prova escrita e tratavam de um aspecto já visto no bimestre. Com isso, os modelos de prova realizados e as notas obtidas pelos alunos no período em que a coleta de dados estava sendo realizada também foram considerados nesta pesquisa.

Após cada atividade, os alunos responderam a questionários com o objetivo de refletir sobre a atividade e sobre o efeito que ela provocou em sua compreensão do conteúdo em questão. Tais respostas formam também parte dos dados para análise nesta pesquisa. 


\section{Primeira atividade}

$\mathrm{Na}$ primeira atividade, foi feito o uso da tradução intersemiótica e interlingual como objetivo de revisar os tempos verbais "Simple Past" e "Present Perfect", ambos estudados durante o bimestre. O primeiro tempo verbal estudado com os alunos do oitavo ano e o segundo tempo verbal, com os alunos do nono ano. Participaram desta atividade apenas quatro alunos, pois neste dia uma aluna do oitavo ano faltou.

O primeiro momento da atividade consistiu em uma breve revisão oral e expositiva com o auxílio do quadro branco acerca do uso dos tempos verbais e de suas respectivas estruturas. Os alunos participaram voluntariamente, tornando o momento ainda mais fluido e breve. No segundo momento, foi apresentado o videoclipe oficial e sem legendas da música "I still haven't found what I'm looking for", da banda irlandesa $\mathrm{U} 2$.

Todos os alunos prestaram atenção e, em seguida, houve a discussão oral. $\mathrm{Na}$ discussão, apenas uma aluna do nono ano (aluna A) expôs abertamente suas reflexões sobre o que achou do vídeo e sua opinião sobre o tema da música. A partir dos comentários da aluna $\mathrm{A}$, outra aluna do oitavo ano (aluna $\mathrm{B}$ ) chegou à conclusão de que se tratava de uma música de amor, e os demais colegas concordaram. No entanto, um aluno (aluno C) passou grande parte do momento de discussão em silêncio e não expôs oralmente suas opiniões. Consideramos a personalidade do aluno um fator importante para tal comportamento, pois trata-se de um aluno mais introspectivo que os outros, que não gosta de falar em público e também por sempre apresentar dificuldades na disciplina de língua inglesa.

Após a discussão oral, foi pedido que os alunos escrevessem um parágrafo respondendo as perguntas abaixo:

- Sobre o que fala a música? Por que você tem essa opinião?

- Para quem você acha que essa música foi escrita?

- As imagens te ajudaram a formar essa opinião? 
Figura 1: Videoclipe oficial da música "I still haven't found what I'm looking for"

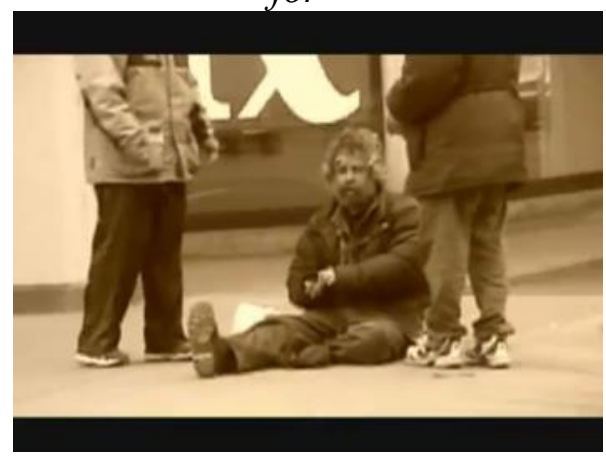

Fonte: 〈https://www.youtube.com/watch?v=Zhi6nNYNOxQ>

Na primeira questão, a aluna A afirmou que a música trata da procura pela pessoa amada, no entanto, a aluna não especificou porque ela tem essa opinião. A aluna afirmou também que, com a ajuda das imagens, conseguiu ter ideias sobre o tema da música. A aluna B, por sua vez, afirmou: "Sem as imagens seria impossível de identificar o que fala a música. Mas com as imagens foi fácil descobrir que a música fala da procura de uma pessoa amada". O aluno D (do nono ano) concordou com as colegas em sua resposta escrita, afirmando que a música fala de amor, pois pelas imagens há uma pessoa à procura de amor, mas que sem as imagens ele não teria sido capaz de fazer tal leitura do vídeo. Apenas o aluno $\mathrm{C}$ discordou e afirmou que a música fala sobre a vida e seus obstáculos. Esse aluno também atribuiu sua interpretação às imagens presentes no vídeo.

A partir das respostas dos alunos, percebemos que o recurso visual, que apoia a tradução intersemiótica em sala de aula, foi a justificativa que embasou as respostas, mas sem uso argumentativo para o estímulo do aprendizado de língua inglesa, que justifique o uso da tradução intersemiótica, provavelmente por não terem a dimensão dessa aplicação. O nível tradutório para preparação das atividades deve ser de consciência e domínio do professor e não do aluno. Na verdade, a partir da relação entre o signo verbal (letra da música) e o não verbal (imagens presentes no videoclipe), os alunos se sentiram mais motivados à discussão, tirando conclusões e debatendo o que viram no videoclipe. A letra da música, como mencionado anteriormente, trata do tema “amor" em sentido mais amplo, refletindo sobre a vida. Romanelli (2006) afirma que é importante que em níveis iniciais a tradução seja usada para superar dificuldades na LE. Sem o uso da tradução intersemiótica, nessa atividade, os alunos teriam tido maior 
dificuldade em desenvolver a leitura da letra da música apresentada, bem como para trabalhar o tempo passado em inglês. O recurso das imagens possibilitou associações e possibilidades de significado para aos poucos criarem uma interpretação da música trabalhada em sala de aula.

Em seguida, os alunos assistiram a uma versão do mesmo videoclipe com legendas em português para que pudessem fazer a relação das imagens apresentadas com a tradução da letra da música. Após assistirem, os alunos escreveram outro parágrafo respondendo às seguintes perguntas:

- Você mudou de opinião? Se sim, o que fez você mudar de opinião?

- Para quem você acha que essa música foi escrita?

Em seus comentários, a maioria dos alunos expressou surpresa sobre o real tema da música, afirmando terem mudado de opinião através da associação das imagens com a legenda em português. Os alunos mencionaram diferentes suposições sobre o tema da música como: o amor de Deus; Bem vs. Mal; e o amor "não romântico" (de acordo com os alunos, o amor que não se trata de uma relação entre homem e mulher).

Por meio das respostas foi possível perceber que três dos quatro alunos mudaram sua opinião no que diz respeito ao tema da música, e todos alegaram que tal mudança ocorreu devido ao uso do vídeo com as legendas em português. Tal fato reforça a importância do uso da tradução interlingual (LM) em níveis iniciais de aprendizagem. Romanelli (2006, p. 4) explica que "quanto mais diferentes forem as estruturas gramaticais e lexicais de duas línguas, maior necessidade haverá de um uso frequente da tradução nos níveis iniciais". Considerando as diferenças estruturais entre as línguas inglesa e portuguesa, é importante destacar que o uso da LM se faz necessário sobretudo devido ao nível inicial de aprendizado no qual os alunos se encontram.

De acordo com Branco (2009, p. 191), um aluno tentando se comunicar na LE, ainda preso à sua LM, vai buscando construir ideias comparando as estruturas das duas línguas, de forma que sejam semelhantes tanto na estrutura quanto no significado. Logo, é nesta fase que o professor deve iniciar o processo de distinção da LE e da LM, para que o aluno possa utilizar a proximidade de significado e não de estruturas linguísticas. Dessa maneira, o professor pode fazer uso da interlíngua a seu favor, como auxílio no ensino de LE. 
No terceiro momento da atividade, o foco foi na estrutura gramatical e no uso dos tempos verbais "Simple Past" e "Present Perfect", que vinham sendo abordados com os alunos do oitavo e nono ano, respectivamente. Os alunos deveriam responder a terceira e a quarta questão da atividade. Na terceira questão, foi pedido aos alunos do oitavo ano que identificassem na letra da música (desconsiderando as repetições) verbos no "Simple Past" e os alunos do nono ano identificassem verbos no "Present Perfect".

Na quarta questão, os alunos deveriam ler a letra da música mais uma vez e escrever um parágrafo que respondesse às seguintes perguntas sobre a primeira e a oitava estrofe:

- Qual o tempo verbal predominante?

- Por que você acha que esse tempo verbal foi escolhido?

- Na tradução, os tempos verbais são mantidos como no original?

A aluna B, que apresentou problemas para identificar os verbos na questão anterior, também mostrou dificuldades ao responder essa questão. Apesar de ter sido capaz de identificar os dois tempos verbais, a aluna apresentou respostas incompletas e justificativas vagas para o uso dos mesmos, deixando claro que tinha dúvidas quanto ao seu uso. Para tal resultado pudemos atribuir uma série de fatores: a timidez, pois mesmo com dúvidas optou por não as expor na revisão oral que havia acontecido no começo da aula; a falta de hábito em participar de atividades com músicas e vídeos em inglês, o que pode ter acarretado em ansiedade, deixando a aluna nervosa, prejudicando seu desempenho na atividade. Stibbard (1998) explica que:

[...] a justificativa para o uso da tradução é encontrada também pelo papel que lhe é atribuído nas abordagens afetivo-humanistas no ensino de inglês como LE, que enfatizam a necessidade de reduzir a ansiedade nas fases iniciais da aprendizagem de línguas, permitindo uso de língua materna (STIBBARD, 1998, p. 71).

Logo, o uso da LM se faz importante nesse contexto para que os alunos se sintam confortáveis, e não intimidados pela LE. Tal uso poderá possibilitar um ambiente de sala de aula mais propício para desenvolver uma atividade em que eles participem e tenham maior êxito. No entanto, o uso da LM não foi totalmente efetivo se considerarmos o desempenho da aluna B nesta questão. Para este resultado consideramos o fator "motivação", pois previamente a aluna afirmou não se interessar 
pela língua inglesa, o que possivelmente lhe trouxe problemas durante as atividades. Tal fator pode ser uma variável considerada difícil de ser mudada, e por vezes alheia ao papel do professor e de sua metodologia.

No último momento da aula, houve uma reflexão oral acerca da atividade através de um questionário. Em suas respostas, todos os alunos afirmaram terem gostado da atividade e que a mesma teve um impacto positivo em sua aprendizagem. No entanto, a aluna B afirmou que apesar da atividade ter ajudado sua compreensão, ela continuou com dúvidas.

A atividade foi utilizada como uma das avaliações bimestrais e seu valor era 5,0 (cinco) e, juntamente com outras atividades realizadas em sala, formaram uma nota. Posteriormente foi realizada uma prova também sobre o mesmo assunto abordado na atividade, de valor 10,0 (dez), que formou a segunda nota para calcular a média bimestral dos alunos. $\mathrm{O}$ aluno que não atingisse a média 7,0 (sete) nessa prova tinha direito a fazer uma prova de recuperação. A Tabela 1 apresenta o desempenho dos alunos no $1^{\circ}$ bimestre:

Tabela 1: Desempenho dos alunos no $1^{\circ}$ bimestre

\begin{tabular}{|c|c|c|c|}
\hline ALUNO & $\begin{array}{l}\text { ATIVIDADE } \\
\text { DO DIA } 06 \text { DE } \\
\text { ABRIL }\end{array}$ & $\begin{array}{c}\text { PROVA } \\
\text { DO DIA } 13 \text { DE } \\
\text { ABRIL }\end{array}$ & $\begin{array}{c}\text { RECUPERAÇÃO } \\
\text { DO DIA } 20 \text { DE } \\
\text { ABRIL }\end{array}$ \\
\hline Aluna A & 4,0 & 8,0 & --- \\
\hline Aluna B & 4,0 & 5,5 & 6,0 \\
\hline Aluno C & 4,0 & 4,5 & 6,5 \\
\hline Aluno D & 3,0 & 7,0 & --- \\
\hline
\end{tabular}

Fonte: Elaboração própria

Na Tabela 1, é possível ver o desempenho dos alunos após a atividade de tradução sobre o assunto estudado no bimestre. Dos quatro alunos que participaram da atividade, três obtiveram resultados positivos na prova bimestral. Embora os alunos tenham apresentado dificuldades na atividade, ela teve um impacto positivo, auxiliandoos não só naquele momento, mas também na prova bimestral, na qual mais da metade dos alunos obteve resultados positivos. Romanelli (2006, p. 7) explica que "as atividades com tradução podem ser usadas para encorajar os estudantes a assumirem riscos e não tentarem evitá-los. É uma forma de estimular os alunos a forçarem o seu 
conhecimento o máximo possível para superar suas dificuldades [...]”. Desse modo, mesmo $50 \%$ dos alunos não obtendo resultados positivos como o esperado, isso mostra que os mesmos se arriscaram tentando superar suas dificuldades.

\section{Segunda atividade}

A segunda atividade teve como objetivo trabalhar a compreensão de uma charge em inglês, atentando para aspectos gramaticais, linguísticos e semânticos. Em seguida, os alunos deveriam produzir uma versão da mesma charge em Português. $O$ foco gramatical nesta atividade foi no uso dos tempos "Past Perfect" e "Simple Past", que ainda vinham sendo estudados nas aulas anteriores àquela em que a atividade foi realizada. Neste dia, todos os alunos compareceram. A charge é apresentada a seguir:

Figura 2: Charge utilizada na tirinha

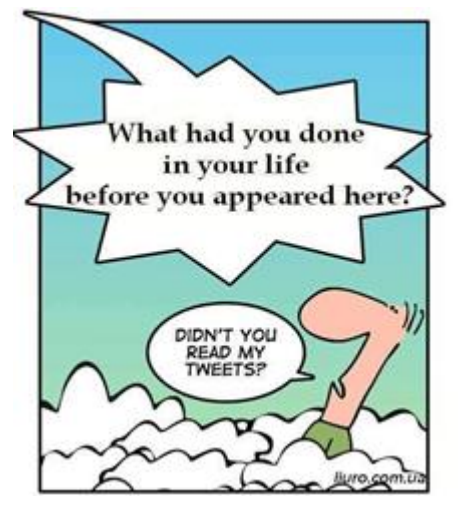

No primeiro momento, foi feita uma revisão oral, perguntando aos alunos o que eles lembravam sobre a estrutura e sobre o uso dos dois tempos verbais que vinham sendo estudados nas últimas aulas. No segundo momento, foi proposto que os alunos se dividissem em dois grupos (uma dupla e um trio) de modo que os do oitavo ano ficassem com pelo menos um aluno do nono ano para que houvesse a leitura da charge e uma breve discussão geral. Em seguida, os alunos deveriam responder por escrito às seguintes perguntas:

- O que é uma charge?

- Qual a sua função? 
- Você conseguiu perceber a mensagem que o autor da charge quis passar?

- Se sim, qual?

Através das respostas pudemos observar que ambos os grupos conheciam o gênero e expressaram muito bem o que sabiam sobre ele. No entanto, apenas o grupo 1 (dupla) soube expressar vagamente qual a mensagem que o autor quis passar com essa charge, afirmando que: "Deus sabe de tudo e vê tudo, mas ele ainda perguntou o que houve para ele aparecer". A idade dos alunos pode ter sido um fator decisivo para este resultado.

Legutke (2012, p. 112) explica que independentemente das diferenças culturais, adolescentes dividem a experiência de estarem transitando da infância para a fase adulta, através das fases da puberdade e da adolescência. Esse período de transição influencia também sua posição dentro de sala de aula. Nesta atividade, por exemplo, os alunos compreenderam a crítica à sociedade que atualmente expõe suas vidas nas redes sociais, visto que eles mesmos se identificaram como indivíduos que fazem parte deste grupo de pessoas. Contudo, pelo fato de ainda estarem em um período transitório entre a infância e a adolescência, eles não foram capazes de elaborar tal pensamento de modo que ficassem claras suas posições a essa crítica.

No terceiro momento, os grupos ficaram encarregados de traduzir o texto presente na charge para sua LM, com o auxílio de dicionários, atentando para possíveis perdas e devidas alterações, se necessárias. Na tradução da charge para a língua portuguesa, ambos os grupos foram bem-sucedidos e conseguiram manter a mensagem a ser passada e respeitando aspectos gramaticais e semânticos, como é possível ver na tabela a seguir:

Tabela 2: Tradução dos alunos da charge

\begin{tabular}{|l|c|}
\hline \multicolumn{1}{|c|}{ Grupo } & \multicolumn{1}{c|}{ Tradução } \\
\hline Grupo 1 - alunos C e D & $\begin{array}{c}\text { O que você fez na sua vida que te trouxe aqui? } \\
\text { - Você não viu meu post no twitter? }\end{array}$ \\
\hline Grupo 2 - alunas A, B e E & $\begin{array}{c}\text { - O que você fez da sua vida antes de aparecer aqui? } \\
\text {-Você não viu os meus tweets? }\end{array}$ \\
\hline
\end{tabular}

Fonte: Elaboração própria 
Podemos observar que o Grupo 1 fez uma pequena mudança no que diz respeito à pergunta presente no texto original da charge, no qual Deus pergunta ao homem o que ele fez durante sua vida até aquele momento em que ele havia chegado ao céu. $\mathrm{Na}$ tradução produzida por esse grupo, a pergunta foi modificada de modo que Deus quis saber o que o homem fez que o levou até ali. O Grupo 2, por sua vez, produziu uma tradução literal, o que também não se mostrou ser um problema, pois todos os aspectos já mencionados foram mantidos. O grupo fez uso do dicionário em excesso para produzir sua tradução. Através das notas de campo, e do resultado apresentado, pode-se dizer que as alunas fizeram grande uso de tradução interiorizada. Navarrete (1997 apud LUCINDO, 2006, p. 4) afirma que "em níveis iniciais a tradução interiorizada ocorre quase em todos os momentos, pois o aluno traduz tudo ou quase tudo".

No quarto e último momento da aula, todos os alunos responderam ao questionário com o objetivo de refletir sobre a atividade. Todos os alunos afirmaram que a atividade contribuiu de forma positiva para sua aprendizagem como é possível ver na tabela a seguir:

Tabela 3: Resposta dos alunos para a questão 5 do questionário da segunda atividade

\begin{tabular}{|c|c|}
\hline Aluno & Resposta \\
\hline Aluna A & $\begin{array}{l}\text { "Eu gostei, pois muitas de minhas dúvidas foram tiradas. E aprendi coisas que } \\
\text { ainda não sabia." }\end{array}$ \\
\hline Aluna B & "Eu acho que foi muito útil, as atividades de tradução são bem legais." \\
\hline Aluno C & $\begin{array}{l}\text { "Sim, me ajudou bastante pois eu tinha dificuldade em diferenciar os tempos } \\
\text { [verbais] mas agora consigo compreender mais ou menos o assunto e evoluí muito } \\
\text { com a professora." }\end{array}$ \\
\hline Aluno D & $\begin{array}{l}\text { "Sim, me ajudou bastante, pois tenho muita dificuldade em diferenciar [os } \\
\text { tempos verbais], mas depois fiquei entendendo bem melhor." }\end{array}$ \\
\hline Aluna A & "Eu consegui aprender muitas coisas, me ajudou bastante." \\
\hline
\end{tabular}

Fonte: Elaboração própria

As respostas ao questionário foram consideradas positivas, pois apesar de alguns alunos continuarem com dúvidas após a atividade, todos afirmaram que a atividade contribuiu para tornar sua compreensão mais clara. Esta atividade teve valor 3,0 (três) e, juntamente com a terceira atividade de tradução realizada posteriormente, formou a 
primeira nota do segundo bimestre. Os resultados foram positivos, pois todos os alunos obtiveram nota 2,5 (dois e meio). Consideramos essa atividade bem-sucedida, pois os alunos conseguiram produzir traduções coerentes, respeitando aspectos sintáticos e semânticos de ambas as línguas.

\section{Terceira atividade}

A terceira e última atividade teve como objetivo trabalhar a compreensão da tirinha em inglês abaixo, atentando para aspectos gramaticais, linguísticos e semânticos; produzir uma versão da mesma charge em português e comparar com a tradução original publicada atentando para as diferenças e semelhanças. O enfoque gramatical foi o uso do modal "Will" e da expressão "Going to" para expressar ações no futuro, que vinham sendo estudados por ambas as séries. A tirinha é apresentada a seguir:

Figura 3: Tirinha em inglês utilizada na atividade

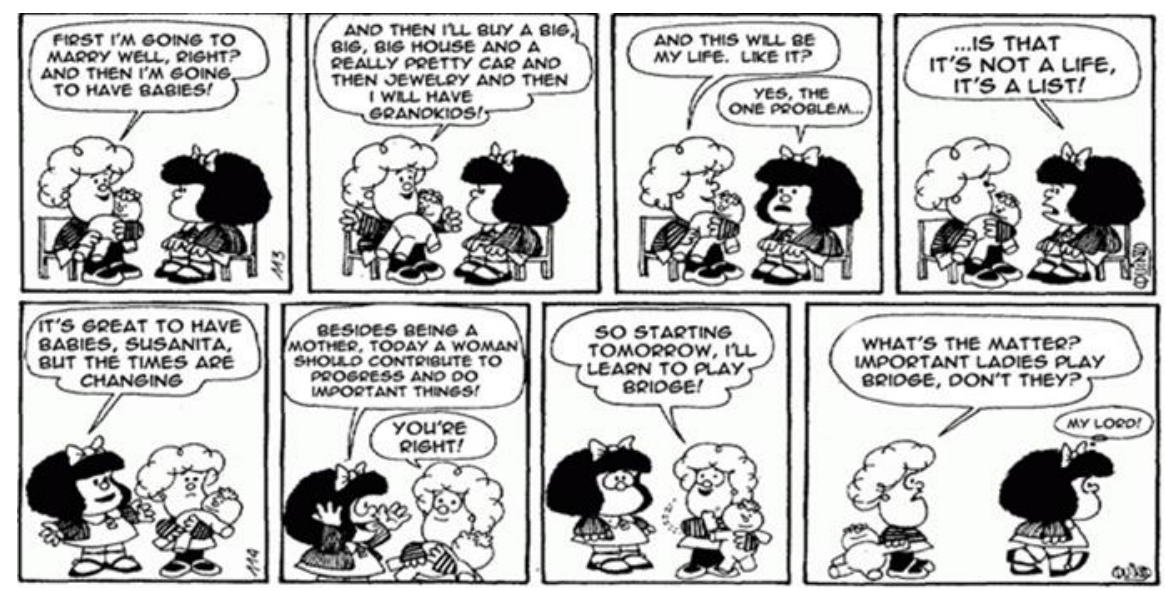

Fonte: http://pipinglesmontecarmelo.blogspot.com

O primeiro momento foi de contextualização e sondagem a respeito do que os alunos conheciam sobre o gênero textual e do personagem Mafalda. Após uma breve discussão acerca do gênero textual e da personagem, a atividade seguiu para o segundo momento. No segundo momento, foi proposto que os alunos se dividissem em dois grupos, uma dupla e um trio, como na atividade anterior, para fazer a leitura conjunta da tirinha. No segundo momento, em grupos, os alunos fizeram uma leitura conjunta paralelamente com uma discussão que envolveu aspectos sociais respondendo às 
perguntas: "Qual a mensagem da tirinha?", e "Qual relação podemos fazer entre a conversa de Mafalda e Susanita e a visão da mulher na sociedade?”.

Em seguida, os alunos responderam à questão número dois da atividade, na qual eles deveriam identificar na tirinha frases usando o modal "Will" e a expressão "going to" indicando ações no futuro. Ambos os grupos foram bem-sucedidos nessa parte, identificando corretamente todas as estruturas pedidas e alcançando as expectativas. $\mathrm{O}$ terceiro momento da atividade foi o momento dedicado à produção. Ambos os grupos traduziram a tirinha para português com o auxílio de dicionários.

O resultado foi positivo nas duas traduções, pois ambos os grupos apesar da grande dificuldade conseguiram produzir uma tradução satisfatória no que diz respeito ao vocabulário, estruturas gramaticais e aspectos semânticos mantendo a mensagem que o autor quis passar, assim como o lado cômico. Costa (1988 apud KIMINAMI; CANTAROTTI 2014, p .44) afirma que a tradução de textos em LE para a LM é uma ferramenta produtiva para avaliar a competência escrita dos alunos e também para a sua compreensão de características distintas entre sua língua e cultura, considerando a língua e a cultura estrangeira.

O Grupo 1 foi bem-sucedido na sua tradução no que diz respeito à estrutura e vocabulário, no entanto alternou a ordem das falas na conversa entre Mafalda e Susanita, o que tornou o texto um pouco confuso, como é possível ver na Tabela 4 a seguir:

Tabela 4: Tradução produzida pelo grupo 1

\begin{tabular}{|l|l|}
\hline \multicolumn{1}{|c|}{ Grupo } & \multicolumn{1}{c}{ Tradução produzida pelo grupo } \\
& - Primeiro vou me casar sabe? Depois vou ter filhos. Depois vou comprar uma casa \\
& bem grande e um carro bem bonito, depois jóias e vou ter netinhos. \\
& - Ter filhos é ótimo, mas os tempos mudam. Além de ser mãe a mulher tem que \\
& fazer coisas importantes. \\
GRUPO 1 & - Tem razão! \\
(Alunos C e D) & - Minha vida vai ser assim. \\
& - Único defeito ... \\
& - Isso não é uma vida, é uma lista! \\
& - Amanhã vou aprender a jogar cartas. \\
& - Por acaso as mulheres importantes não jogam bridge? \\
& - Meu Deus
\end{tabular}

Fonte: Elaboração própria 
O grupo 2 também fez uma tradução satisfatória, mas em uma tentativa de manter a estrutura da tirinha com os quadrinhos e os balões de fala, deixou o texto um pouco desorganizado, prejudicando a apresentação e também a leitura. Como é possível ver na figura abaixo:

Figura 4: Tradução produzida pelo grupo 2

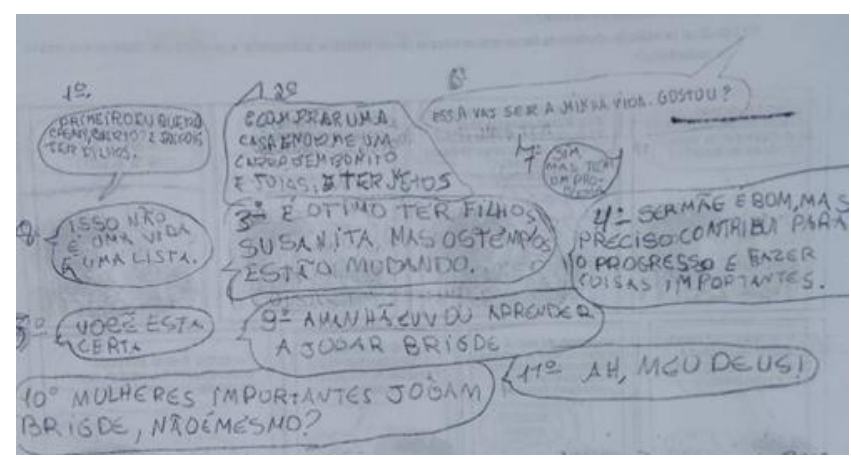

No momento seguinte, os alunos compararam suas traduções entre si e depois compararam suas traduções com a tradução publicada em português.

Figura 5: Tirinha em português utilizada na atividade

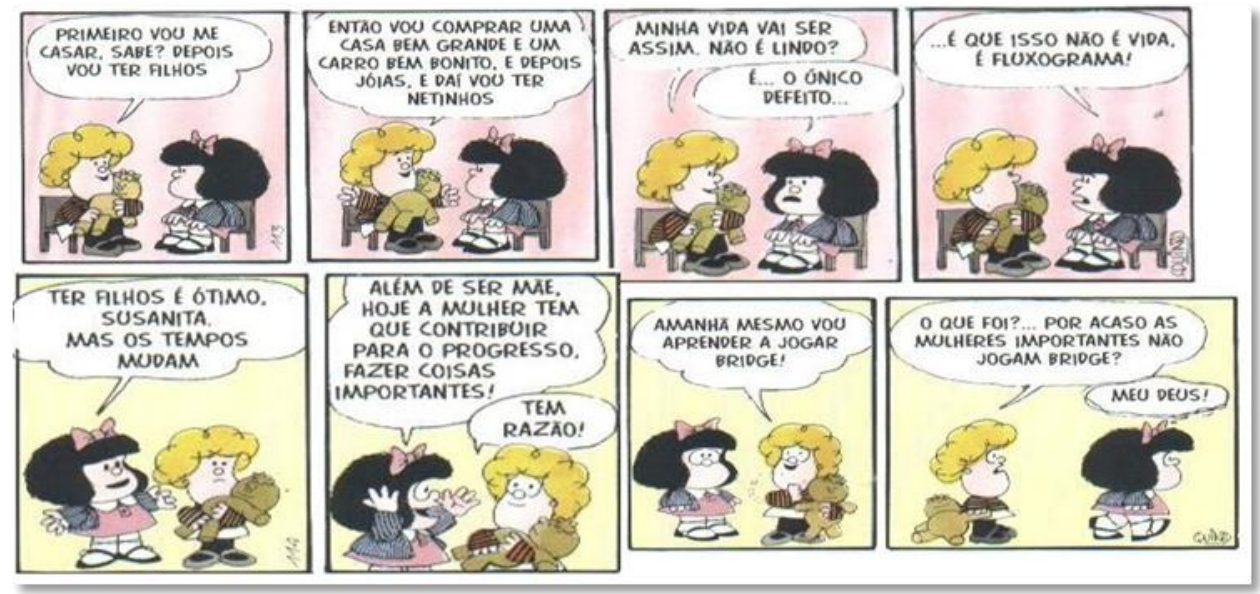

Fonte: http://analisebakhtin.wordpress.com

Por fim, no quarto e último momento da atividade da aula, os alunos responderam a um questionário com o objetivo de refletir sobre a atividade; assim como na atividade anterior, o total foi de cinco questionários respondidos. Em suas respostas, apenas duas alunas consideraram a atividade pouco válida, pois mesmo depois do exercício continuaram com dúvidas no assunto. No entanto, todos afirmaram que apesar 
da dificuldade a atividade teve seu aspecto positivo como é possível ver na tabela a seguir:

Tabela 5: Respostas da questão 5 do questionário na terceira atividade

Aluno Resposta

Aluna A "Eu gostei da atividade, apesar das dificuldades."

Aluna B "Eu achei que ajudou um pouco, mas ainda tenho algumas dúvidas. "

Aluno C "Ajudou porque consegui entender a diferença e colocar na forma negativa e positiva e etc. E consegui diferenciar [o uso de Going To e Will]."

Aluno D "Me ajudou muito a traduzir, fiquei conhecendo novas palavras."

Aluna E "Ajudou um pouco, compreendi algumas coisas."

Fonte: Elaboração própria

Através das respostas dos alunos, é possível perceber que todos sentiram dificuldade nesta atividade, visto que não estão acostumados a traduzir um texto tão grande. No que diz respeito ao desempenho após as atividades, duas alunas não obtiveram êxito na prova bimestral mesmo após a atividade de tradução. Ambas as alunas são do oitavo ano e para tal resultado consideramos dois possíveis motivos: a falta de familiaridade com atividades de tradução e a falta de interesse em aprender a língua inglesa. Em atividade anterior, as duas alunas afirmaram não gostarem da língua inglesa por não se identificarem e/ou acharem difícil. Tal aspecto pode gerar um bloqueio ou até mesmo uma aversão à aprendizagem da língua e é uma variante que foge do controle do professor. No entanto, os outros alunos obtiveram resultados acima da média, mesmo alguns declarando não se interessarem pelo idioma.

Barker (2002 apud SVÄRD, 2007) afirma que em turmas desniveladas pode ser difícil manter a atenção de todos os alunos. Em uma turma desnivelada como essa é preciso considerar o fato de que cada aluno está em um nível de aprendizagem diferente, sendo assim, é difícil manter a atenção de todos, o que muitas vezes repercute em resultados distantes, como ocorreu nas atividades aplicadas.

\section{Conclusão}


Este artigo se propôs a analisar a eficácia do uso de tradução como ferramenta em uma sala de aula de língua inglesa como LE em uma escola regular particular na cidade de Lagoa Seca, no estado da Paraíba. Através de atividades de tradução envolvendo as categorias de tradução interlingual e intersemiótica, propostas por Jakobson (2000), de aplicação de questionários, notas de campo e análise dos resultados das provas bimestrais dos alunos, buscamos mostrar que a tradução pode ser usada como auxílio no presente contexto. O contexto onde as atividades foram aplicadas enquadra-se no que Svärd (2006) explica ser mixed-abilities, sendo os alunos enquadrados em diferentes níveis de aprendizagem. Ainslie (1994 apud SVÄRD, 2007) conceitua "mixed-ability classes" como turmas com alunos que diferem em habilidades, motivação, interesses, níveis de ansiedade e entre outros aspectos. Percebemos que este foi um fator decisivo para as respostas obtidas.

Através das categorias de tradução intralingual, interlingual e intersemiótica observamos que a tradução pode ser usada como ferramenta no ensino de LE. Como explica Lucindo (2006), os exercícios de tradução são uma atividade frequente em sala de aula no ensino de LE. A autora afirma que os exercícios de tradução colaboram para a conscientização ideal para cada tipo de texto, ajudam na formação da consciência crítica da cultura da LE, e também permitem uma participação mais ativa dos alunos.

Tal afirmação também corrobora o fato de que dos quatro alunos que afirmaram não sentirem interesse, todos participaram ativamente das atividades e se esforçaram para que suas dúvidas fossem solucionadas. A análise das notas das provas bimestrais mostra também que pelo menos três dos cinco alunos participantes da pesquisa obtiveram nota média e/ou acima da média exigida pela escola, o que mostra que as atividades de tradução auxiliaram esses alunos em compreender melhor os assuntos estudados.

Popovic (2001, p. 5) explica que a tradução pode ser utilizada para provocar discussões e ajudar professores e alunos a se conscientizarem da interação inevitável entre LM e LE que ocorre no processo de aprendizagem da língua. Sendo assim, podese afirmar que a prática da tradução em sala de aula de LE é algo aceitável e benéfico para professores e alunos. Logo, destacamos a importância e a necessidade de estudos na área de tradução no ensino de LE a fim de que a tradução possa ser incluída de maneira consciente na sala de aula por professores e alunos. Destacamos também a 
relevância do estudo das categorias de tradução como auxílio para professores, com o objetivo de que os mesmos façam uso da tradução como ferramenta para o ensino de língua inglesa de maneira adequada e com objetivos claros, tornando a aprendizagem de seus alunos cada vez mais positiva.

AGRADECIMENTOS: Agradecemos ao POSLE-UAL-CH-UFCG, pelo apoio recebido para o desenvolvimento deste trabalho, bem como aos alunos que nos auxiliaram, ora na coleta, ora na aplicação e discussão das atividades, autorizando o uso de dados coletados das aulas para esta publicação. Agradecemos, também, o apoio do Grupo de Pesquisa cadastrado no CNPq Tradução: Teoria, Prática e Formação do Professor.

\section{REFERÊNCIAS}

AUMONT, Jacques. A imagem. Campinas: Papirus, 1993. Tradução: Estela dos Santos Abreu e Cláudio C. Santoro.

BRANCO, Sinara Oliveira. Teorias da tradução e o ensino de língua estrangeira. Revista Horizontes de Linguística Aplicada, v. 8, n. 2, p. 185, 2009.

BRANCO, Sinara Oliveira. The application of intersemiotic translation combined with multimodal activities in the English as a foreign language classroom. Revista Brasileira de Linguística Aplicada, v. 14, n. 2, p. 293-312, 2014.

JAKOBSON, Roman. On linguistic aspects of translation. In: VENUTI, Lawrence (Org.). The translation studies reader. London: Routledge, 2000. p. 113-118.

KIMINAMI, Aline Yuri.; CANTAROTTI, Aline. Tradução e Ensino de Língua Estrangeira - Possibilidades e direcionamentos. In: CARVALHO, Tatiana de Lourenço. PONTES, Valdecy de Oliveira (Org.). Tradução e ensino de línguas - Desafios e perspectivas. Mossoró: UERN, 2014. p. 40-54.

LEFFA, Vilson J. Metodologia do ensino de línguas. In: BOHN, H. I.; VANDRESEN, P. Tópicos em linguística aplicada: $\mathrm{O}$ ensino de línguas estrangeiras. Florianópolis: Ed. da UFSC, 1988. p. 211-236.

LUCINDO, Emy Soares. Tradução e ensino de línguas estrangeiras. Scientia Traductionis, Santa Catarina, n. 3, 2006.

MALMKJAER, Kirsten (Org.) Translation \& language teaching. Reino Unido: St Jerome Publishng, 1998. p. 1-11.

MALMKJAER, Kirsten. Language learning and translation. In: GAMBIER, Yves.; VAN DOORSLAER, Luc (Ed.). Handbook of translation studies. John Benjamins Publishing, 2010. p.185-190 
PEREIRA, Elisabete Francisca de Oliveira. O Papel da Língua Materna na aquisição da língua estrangeira. Revista Inter Ação, v. 26, n. 2, p. 53-62, 2007.

POPOVIC, Radmila. The place of translation in language teaching. Bridges, v. 5, p. 3-8, 2001.

RICHARDS, Jack C.; RODGERS, Theodore S. Approaches and methods in language teaching: a description and analysis. Cambridge: Cambridge University Press, 1986.

ROMANELLI, Sergio. Traduzir ou não traduzir em sala de aula? Eis a questão. Inventário (UFBA), Salvador, v. 05, não paginado, 2006.

ROMANELLI, Sergio. O uso da tradução no ensino-aprendizagem das línguas estrangeiras. Revista Horizontes de Linguística Aplicada, v. 8, n. 2, p. 200, 2009.

SVÄRD, Ann-Christin. The challenge of mixed-ability classes: How should upper secondary English teachers work in order to help the weaker students? Trabalho de conclusão de curso, Högskolan för lärande och kommunikation, Jönköping University/Suécia, 2007.

TEIXEIRA, Augusto Francisco. O pós-método e o ensino de língua inglesa. Revista Avepalavra, v. 11, n. 1, 2011.

\section{Como referenciar este artigo}

BRANCO, Sinara de Oliveira.; SANTOS, Luciana Soares dos. O uso de atividades de tradução intersemiótica e interlingual em uma sala de aula de língua inglesa como le. Rev. EntreLínguas, Araraquara, v. 3, n. 2, p. 203-226, jul./dez. 2017. Disponível em: <https://doi.org/10.29051/rel.v3.n2.2017.9229>. E-ISSN: 2447-3529.

Submetido em: 17/01/2017

Revisões requeridas: 01/03/2017

Aprovado em: 24/04/2017 